\title{
Reliability of Inversely Reconstructed Soil Moisture Profiles and Consequences for Field Applications
}

\author{
M. Johst ${ }^{1 *}$, M.C. Casper ${ }^{1}$ and S. Schlaeger ${ }^{2}$ \\ ${ }^{1}$ University of Trier, Physische Geographie, Campus II, D-54286 Trier, Germany \\ ${ }^{2}$ SCHLAEGER - mathematical solutions \& engineering, Lammbergweg 23, D-32805 Horn-Bad Meinberg
}

\begin{abstract}
The so called Spatial-TDR system allows a monitoring of transient soil moisture profiles. Using a fast inversion algorithm it is possible to reconstruct the electrical properties along a probe in homogenous materials. To evaluate the applicability of the Spatial-TDR under field conditions different laboratory experiments were carried out in this study. The measurements were made with $60 \mathrm{~cm}$ long three-rod probes. A changing water table has been simulated in soil columns filled with homogeneous and layered silt and sand. Besides the impact of the soil heterogeneity the effect of a changed probe geometry and an air gap along the probe were investigated.

For straight probes with good soil contact the reconstructed soil moisture values were very reliable for the homogeneous and layered soil profile. However, the reconstruction algorithm does not cope with discrete changes of impedance along the probe resulting in strong oscillations in the reconstructed moisture profiles. The failure is due to the rather flat edge of the TDR input signal and can not be detected by the optimization approach yet. Discrete changes of the impedance lead to an increasing oscillation of the capacitance that nevertheless give a very good simulation of the TDR waveform. Altogether, the Spatial-TDR measurement system may be very useful to capture temporal and spatial soil moisture dynamics down to $50 \mathrm{~cm}$ depth. The main advantages are the high temporal and spatial resolution. However, it requires further development if one wants to capture accurate absolute soil moisture values.
\end{abstract}

Keywords: Time Domain Reflectrometry, Spatial TDR, soil moisture, soil hydrology, laboratory experiments

\section{INTRODUCTION}

In the last decades, the TDR-technique has been used in various fields e.g. soil hydrological investigations, water balance studies, irrigation, drainage engineering. The ability to monitor continuously soil water content at many sites is one of the main strengths of TDR measurements. The core of a TDR measurement system is a TDR device, generating a voltage pulse and receiving the voltage reflections in time domain. This TDR device is connected to waveguides buried in the observed material. Whenever the impedance along the waveguide changes the electromagnetic pulse is partly reflected and partly transmitted into the waveguide, interacting with the surrounding material. The first clear reflection occurs at the junction between the coaxial cable and the probe (head reflection point). The second, even stronger reflection takes place at the end of the probe (end reflection point). The shape of the reflected signal between these two reflection points, often referred to as TDR waveform, TDR trace or reflectogram is a kind of finger print of the dielectric profile along the rods that again is dependent mainly on the water content. However, the soil moisture profile can not be derived directly from the TDR waveform but has to be calculated by inverse modelling. The last years, the inverse reconstruction of the TDR-signal was one focus within the TDR research community [1-8]. This analysis of the TDR waveform holds great potential for obtaining far more information than only the mean water content [9].

*Address correspondence to this author at the University of Trier, Physische Geographie, Campus II, D-54286 Trier, Germany; Tel: +49/651/2014507, Fax: +49/651/2013976; E-mail: johstm@uni-trier.de,
Aiming to monitor transient soil moisture profiles at many sites a so called Spatial-TDR has been developed recently at the Technical University of Karlsruhe, Germany [4, $10,11]$. Here, a fast inversion algorithm allows the reconstruction of the distribution of the electrical parameters capacitance and effective conductance respectively along a single probe. This Spatial-TDR measurement system is applied in several ongoing projects for instance to detect leakage in levees [12], to determine snow cover characteristics [13], to capture the spatial heterogeneity of soil moisture at the plot scale [8] as well as to investigate flood generation processes [14].

The TDR-signals are affected by both physical parameters of the surrounding material (temperature, electric conductivity, dielectric permittivity) and uncertainties caused by the installation of the probe (luting and compaction of the soil along the rods, changing geometry of the rods). Furthermore, erosion along the probe rods or the presence of pipes or macropores in the soil may lead to a lacking contact of the probe rods with the soil. According to [15] small air pockets with a diameter smaller than 1.2 times the rod diameter and surrounding less than $30^{\circ}$ of the rod circumfence are not likely to affect the TDR-measurement significantly. Reviews on material related impact factors may be found in [9] and [16]. The consequence of changing probe geometry is demonstrated in [7]. The effect of the soil temperature is discussed in e.g. [17-19].

Our overall motivation in capturing soil moisture data is to relate the runoff of a catchment to the actual soil moisture state. But first, to evaluate the applicability of the SpatialTDR for this project, several investigations have been carried 
out in the laboratory as shown in this article. The aim was (i) to check the reliability and accuracy of the inversely reconstructed soil moisture profiles, (ii) to review occurring measurement problems and other sources of uncertainty, and (iii) to assess the potential of the Spatial-TDR concerning field measurements.

\section{MATERIALS AND METHODOLOGY}

\subsection{Technical Devices and Experimental Setup}

In this study we used a Campbell TDR 100 as pulse generator. This TDR device is connected via multiplexer and coaxial cables to three-rod probes as described by [10], [14] and [20]. The probes are $60 \mathrm{~cm}$ long with a spacing of 2.2 $\mathrm{cm}$ between adjacent rods. Each rod has a total diameter of 7 $\mathrm{mm}$ with a steel core and a PVC-coating of $1 \mathrm{~mm}$ thickness.

The TDR-probes were placed top down in columns that are PVC pipe segments of $80 \mathrm{~cm}$ length and $19 \mathrm{~cm}$ inner diameter (Fig. (1)). The columns were filled with coarse sand and silty sand, respectively. The characteristics of the materials are shown in Table $\mathbf{1}$. The material referred to as dry was not dried in the oven but in the air and therefore there was still very little bound water in it. The capillary fringe has been identified by filling the material into a transparent PVC-tube of $4.3 \mathrm{~cm}$ diameter and putting this tube in a water filled bucket. After an equilibrium was reached the difference between the water level in the bucket and in the tube has been measured.

In this article the results for four different setups are presented. (i) The columns were filled with coarse sand and (ii) with silty sand. (iii) A layered profile was set up consisting of coarse sand in the lower $35 \mathrm{~cm}$, silty sand between $35 \mathrm{~cm}$ and $10 \mathrm{~cm}$ depth and air in the uppermost $10 \mathrm{~cm}$. For the last measurements these $10 \mathrm{~cm}$ were filled up with saturated silty sand, too. The air gap between the probe head and the soil was $1 \mathrm{~cm}$ for the last but one measurement and entirely filled up for the very last measurement. (iv) To simulate a nonparallel geometry of the probe rods as it can happen under field conditions, two stones have been clamped between the rods of one probe resulting in a linear increasing distance of the rods up to about $10 \mathrm{~cm}$ at the tips of the outer rods instead of $6 \mathrm{~cm}$. The stones were located at $55 \mathrm{~cm}$ distance from the probe's head and were about 1 to $2 \mathrm{~cm}$ thick whereas the rod-contact-length was each less than $1 \mathrm{~cm}$. This expanded probe was installed in coarse sand. For the setups (i), (ii) and (iii) TDR-measurements with three TDR-probes were made, each in one column.

For all setups TDR-measurements were conducted for dry and saturated conditions as well as for different water

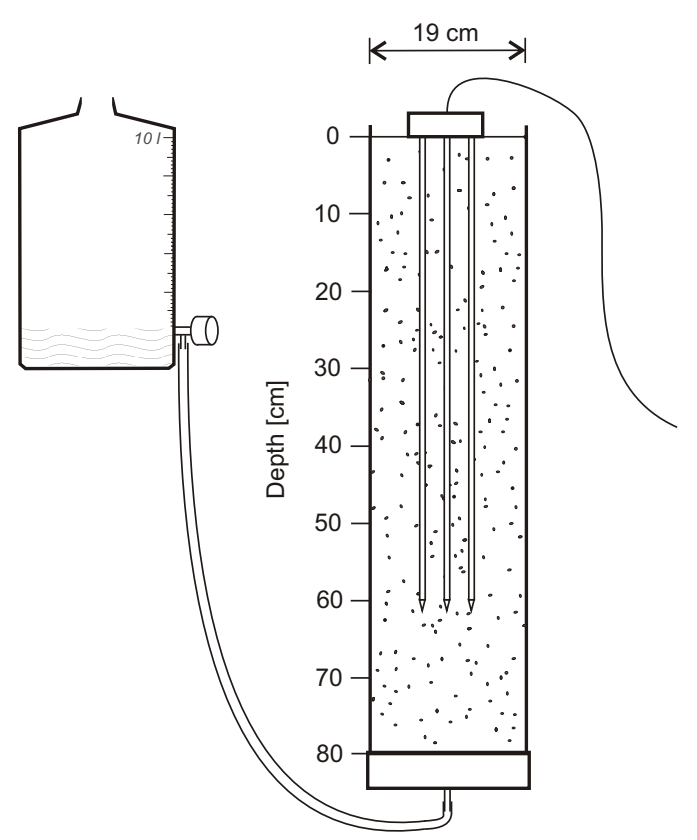

Fig. (1). Experimental setup: One three-rod probe in one soil column, that is watered from below.

levels. Water was supplied from below to avoid air locking in end pores as far as possible. As seen in Fig. (1) a water filled bottle was connected to the outflow at the bottom of the column. For the experiments in coarse sand a second tube was connected to the outflow that allows for an observation of the water level within the column.

All experiments were carried out at a constant air temperature of about $20 \pm 2{ }^{\circ} \mathrm{C}$. The electric conductivity of the supplied water was $17.3 \pm 0.7 \mathrm{mS} \mathrm{m}^{-1}$. The exfiltrating water showed a lower electric conductivity of $14.0 \pm 1.5 \mathrm{mS} \mathrm{m}^{-1}$. A TRIME-FM-TDR with a two rod probe (P2Z) as well as the thermo-gravimetric method were used to get comparative data of the dry and saturated states (Table 3). These measurements have not been done in the soil columns but for six single soil samples of different volume in the magnitude of some litres.

\subsection{Inverse Reconstruction of Soil Moisture Profiles}

The algorithm to reconstruct the soil moisture profile from the TDR waveform is based on the telegraph equations for non-uniform transmission-lines (Eq. (1)). These partial differential equations describes the propagation of a voltage $\mathrm{V}(\mathrm{x}, \mathrm{t})$ and a current $\mathrm{I}(\mathrm{x}, \mathrm{t})$ in time $\mathrm{t}$ and space $\mathrm{x}$ in dependence on four electrical parameters: capacitance $\mathrm{C}$, effective

Table 1. Soil Physical Characteristics of the Used Materials

\begin{tabular}{|c|c|c|}
\hline Soil Characteristic & Coarse Sand & Silty Sand \\
\hline \hline Grain size distribution & $100 \%$ sand $(0.7-1 \mathrm{~mm})$ & $60 \%$ sand, $37 \%$ silt, $3 \%$ clay \\
\hline Bulk density $\left[\mathrm{g} \mathrm{cm}^{-3}\right]$ & $1.61 \pm 0.03$ & $1.73 \pm 0.04$ \\
\hline Water content dried at $20{ }^{\circ} \mathrm{C}[\mathrm{Vol} \%]$ & $0.30 \pm 0.07$ & $0.57 \pm 0.04$ \\
\hline Saturated water content $[\mathrm{Vol} \%]$ & $37.2 \pm 1.2$ & $28.1 \pm 0.6$ \\
\hline Height of capillary fringe $[\mathrm{cm}]$ & $2.0 \pm 0.5$ & $36 \pm 2$ \\
\hline
\end{tabular}




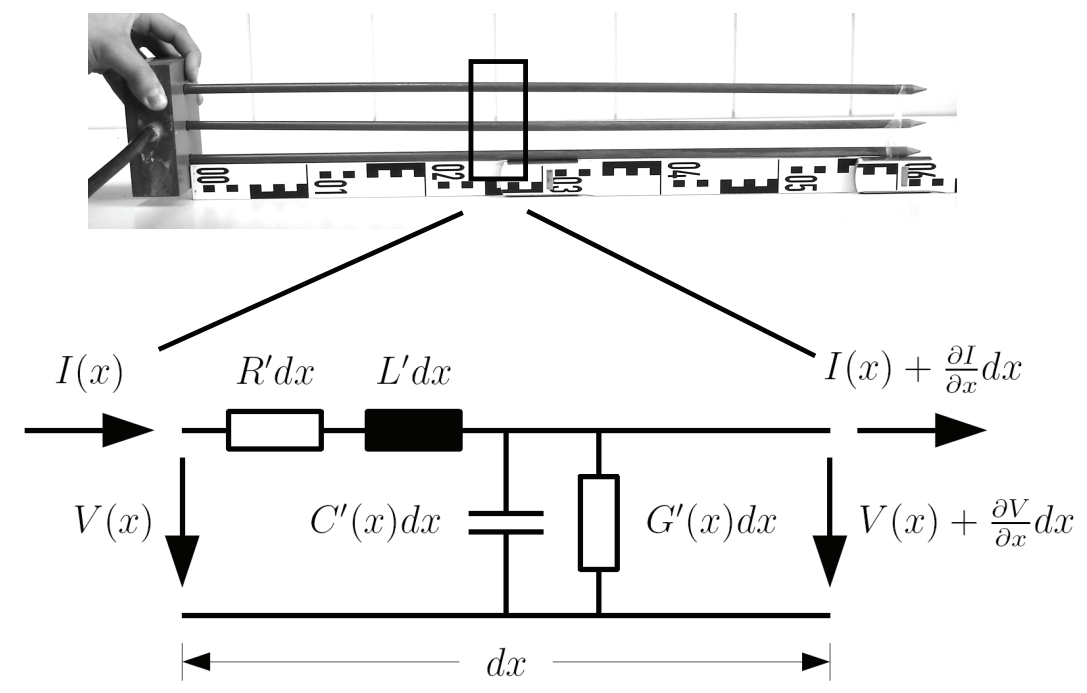

Fig. (2). The simplified moisture probe model consisting of bulk electronic parts. Above: coated $60 \mathrm{~cm}$ long 3-rod-probe (TDR waveguide); below: equivalent circuit of the transmission line [10].

conductance $\mathrm{G}$, inductance $\mathrm{L}$ and resistance $\mathrm{R}$. The equivalent electrical circuit of our three-rod probe is shown in Fig. (2). $\mathrm{C}$ and $\mathrm{G}$ are strongly depending on the water content distribution along the probe whereas $\mathrm{L}$ is assumed to be constant for parallel rods and $\mathrm{R}$ is assumed to be zero for the specific probe.

$$
\begin{aligned}
& \frac{\partial}{\partial x} V(x, t)=-R(x) I(x, t)-L(x) \frac{\partial}{\partial t} I(x, t) \\
& \frac{\partial}{\partial x} I(x, t)=-G(x) V(x, t)-C(x) \frac{\partial}{\partial t} V(x, t)
\end{aligned}
$$

The telegraph equation is solved numerically to simulate a measured TDR waveform [4, 21]. The input signal for the partial differential equation is determined by measuring the TDR-reflections of an open ended coaxial cable with the same length than used for the three-rod probes. To solve Eqs. (1) for the unknown distributions of $C(x)$ and $G(x)$, two independent measurements are actually required, however only one measurement is available. In this study where we focus on the soil moisture we decided to simulate only $\mathrm{C}(\mathrm{x})$ and set $\mathrm{G}$ to zero, since it is likely to be very low for the used materials. Furthermore, the influence of a changing $G$ along the probe is less important for coated rods than for uncoated ones. Generally, a higher water content leads to a clearly higher $\mathrm{C}(\mathrm{x})$ and a slightly higher $\mathrm{G}(\mathrm{x})$.

To determine the capacitance profile $\mathrm{C}(\mathrm{x})$ an optimization approach is used. Starting with an initial guess of $\mathrm{C}(\mathrm{x})$ and $\mathrm{G}(\mathrm{x})$ a simulated TDR-waveform is calculated and compared to the measured one. Using a conjugant gradient method the difference between simulation and measurement is minimized. The gradient can be calculated directly with help of an adjoint boundary value problem (backward problem) associated to the forward problem of TDR-waveform simulation. This directly calculated gradient allows a fast calculation of the solution whereas it cannot avoid the determination to local minima. A detailed description of the optimization algorithm can be found in [4].

Since we applied coated probes the commonly used transformation of the capacitance $\mathrm{C}(\mathrm{x})$ into the dielectric permittivity $\varepsilon(\mathrm{x})$ is not possible. Instead, a probe specific relationship between the total capacitance $C^{\prime}$ and $\varepsilon$ was determined by [10] accounting for the capacitance of the coating. Here, the two constant parameters $C_{1}$ (influence of probe geometry) and $\mathrm{C}_{2}$ (influence of the coating) were derived from calibration measurements of materials with known $\varepsilon$. Using Eq. (2) $\varepsilon(\mathrm{x})$ can be calculated depending on $\mathrm{C}(\mathrm{x})$. Finally, the dielectric permittivity $\varepsilon(\mathrm{x})$ was transformed to volumetric water content $\theta(\mathrm{x})$ by the standard transformation according to [22] as shown in Eq. (3).

$$
1 / C(x)=1 /\left(\varepsilon(x) C_{1}\right)+1 / C_{2}
$$

The values of the electrical parameters used in this study to reconstruct the water content are given in Table 2 . Here, one have to distinguish between the spatial discretization in the algorithm and the resolution of the results. The discretization is the step-size of the numerical algorithm in time and space to solve the forward problem of the wave propagation. Time and space step-size are related by the CourantFriedrichs-Lewy condition. Following a common rule it is appropriate to choose 10 discretization steps for one resolution step. A spatial discretization of $2 \mathrm{~mm}$ results in a resolution 10-20 mm.

$\theta(x)=-5.3 \cdot 10^{-2}+2.93 \cdot 10^{-2} \cdot \varepsilon(x)-5.5 \cdot 10^{-4} \cdot \varepsilon(x)^{2}+4.3 \cdot 10^{-6} \cdot \varepsilon(x)^{3}(3)$

A change of the probe geometry (caused by roots or stones) leads to a variation of inductance $\mathrm{L}$ and probe capacitance $C_{1}$. However, usually one does not know the final geometry of the rods inside the soil. Therefore we assume a parallel geometry and figure out the consequences of these simplifications on the resulting moisture profiles.

\section{RESULTS}

\subsection{Coarse Sand}

The measured TDR waveforms in coarse sand at different stages of water level are shown in Fig. (3). The TDRmeasurements were conducted when the difference in water level in the connected tube was $10 \mathrm{~cm}$. For the probe without rod expansion (Fig. 3a) the TDR-signal between the first and 
Table 2. Fixed Transmission-Line Parameters Used in the Reconstruction Algorithm. $\mathrm{L}, \mathrm{C}_{1}$ and $\mathrm{C}_{2}$ have been Calibrated for this Type of Probe by [10]. Impact of $G$ is Assumed to be Extremely Low Due to Coated Rods and Nearly Lossless Materials

\begin{tabular}{|c|c|}
\hline Parameter & Value \\
\hline \hline Apparent rod length $[\mathrm{mm}]$ & 605 \\
\hline Spatial discretization $[\mathrm{mm}]$ & 2 \\
\hline Inductance $\mathrm{L}\left[\mathrm{nH} \mathrm{m}{ }^{-1}\right]$ & $575 \pm 23$ \\
\hline Resistance $\mathrm{R}\left[\mathrm{Ohm} \mathrm{m^{-1 }}\right]$ & 0 \\
\hline Capacitance $\mathrm{C}_{1}\left[\mathrm{pF} \mathrm{m} \mathrm{m}^{-1}\right]$ & $20.5 \pm 0.9$ \\
\hline Capacitance $\mathrm{C}_{2}\left[\mathrm{pF} \mathrm{m}{ }^{-1}\right]$ & $356 \pm 30$ \\
\hline Effective conductance $\mathrm{G}\left[\mathrm{mS} \mathrm{m}^{-1}\right]$ & 0 \\
\hline
\end{tabular}

second reflection point is constant for the dry and fully saturated profile (bold lines). This proves the assumption that the impact of $\mathrm{G}$ on the signal is negligible in this material.

Fig. (4) shows the finally reconstructed moisture profiles. Considering the middle part of Fig (4a) only $(10$ to $50 \mathrm{~cm}$ depth) the water content of the saturated coarse sand is between 32 and $39 \mathrm{Vol} \%$. This is in the right order of magnitude as seen in Table 3. But the water content is much too high for the uppermost centimetres. This is a result of the discrete change of the line parameters at the beginning of the probe in combination with the dispersion of the input signal. Again, an oscillation of the signal occurs at the probe's end below $50 \mathrm{~cm}$ depth.

\subsection{Silty Sand}

During the measurements in silty sand the water level in the columns could not be observed in a connected tube. Therefore, measurements have been taken in intervals of 10 min and have been stopped as soon as the uppermost soil has been saturated.

The reconstructed soil moisture profiles for one probe are illustrated in Fig. (5). 10 min after water supply some capil- lary water already reaches the lowest $20 \mathrm{~cm}$ of the probe (measurement no. 2). After $60 \mathrm{~min}$ the water level is between 30 and $40 \mathrm{~cm}$ below the probe's head and after $170 \mathrm{~min}$ between 20 and $30 \mathrm{~cm}$. After $230 \mathrm{~min}$ the profile is fully saturated. But again, as described in the previous chapter, the reconstructions in the fully saturated material show an oscillation of the signal in the uppermost and lowest part. The saturated water content between 10 and $50 \mathrm{~cm}$ depth is 23 to $27 \mathrm{Vol} \%$ that is slightly below the reference values given in Table 3 .

\subsection{Layered Profile}

The effect of different material along the rods is visible in the measured TDR waveforms as shown in Fig. (6). Especially for the fully saturated profile i.e. the lower bold line the material boundary is clearly detectable. For measurement no. 4 the discrete change of the water content at the interface of air to wet silty sand is not visible in the TDR waveform. Due to the dispersion of the electromagnetic wave discrete steps are generally smoothed in the signal.

The change in material is evident in the reconstructed moisture profiles, too. The distinct increase of soil moisture in $10 \mathrm{~cm}$ depth (Fig. (7a)) is due to the change from air to silty sand. As seen in Fig. (7b) the change from silty to coarse sand is visible as well. The saturated water content in the silty sand is around $30 \mathrm{Vol} \%$ and increases up to 38 Vol\% in the coarse sand. These values are consistent with the reference values in Table 3 . But again, the signal oscillation is evident in the upper and lower part of measurement no. 6. The oscillation shows the same forming as for the above elucidated oscillations. Again, when the water level reaches the probe's head the reconstructed values are much to high for the uppermost centimetres and consequently too low just beneath. In contrast near the probe's tips the reconstructed signal oscillated towards very low soil moisture values. Furthermore, there is an even stronger oscillating for measurement no. 4 (Fig. (7a)). At this situation the uppermost $10 \mathrm{~cm}$ of the rods are surrounded by air while the underlying $50 \mathrm{~cm}$ of the profile are fully saturated.

b)

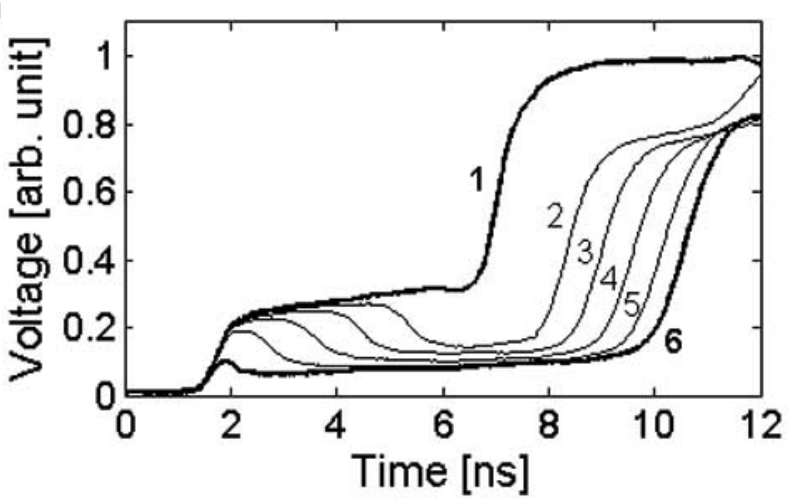

Fig. (3). Measured TDR waveforms for probes installed in coarse sand. Enveloping bold lines are dry (waveform no. 1) and fully saturated (waveform no. 6) profiles. Water level for waveforms no. 2: $40 \mathrm{~cm}$, no. 3:30 cm, no. 4: $20 \mathrm{~cm}$ and no. $5: 10 \mathrm{~cm}$ below the probe's head. a) Constant probe geometry: straight rods.

b) Changed probe geometry: expanded rods (distance of outer tips $10 \mathrm{~cm}$ instead of $6 \mathrm{~cm}$ ). 
a)

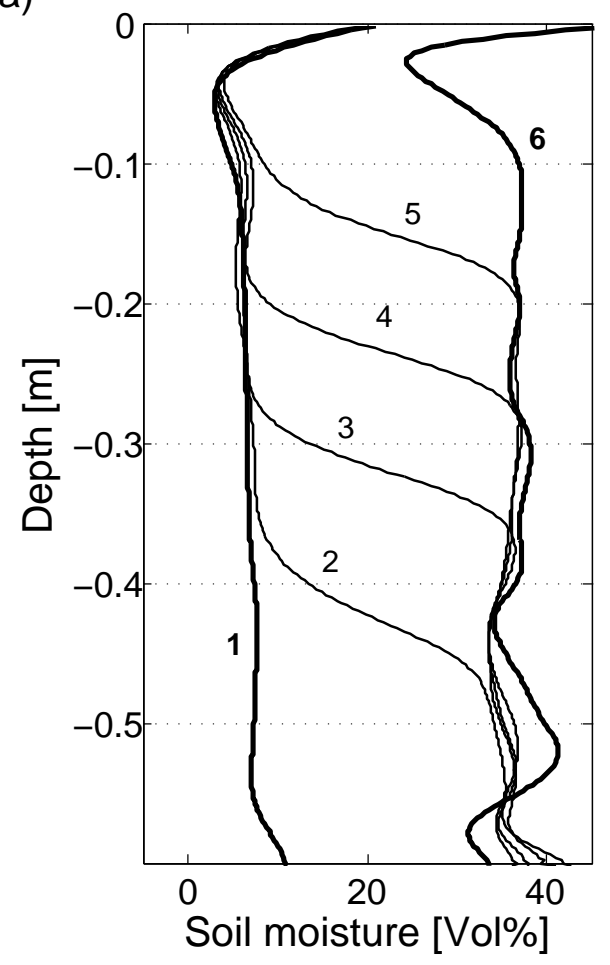

b)

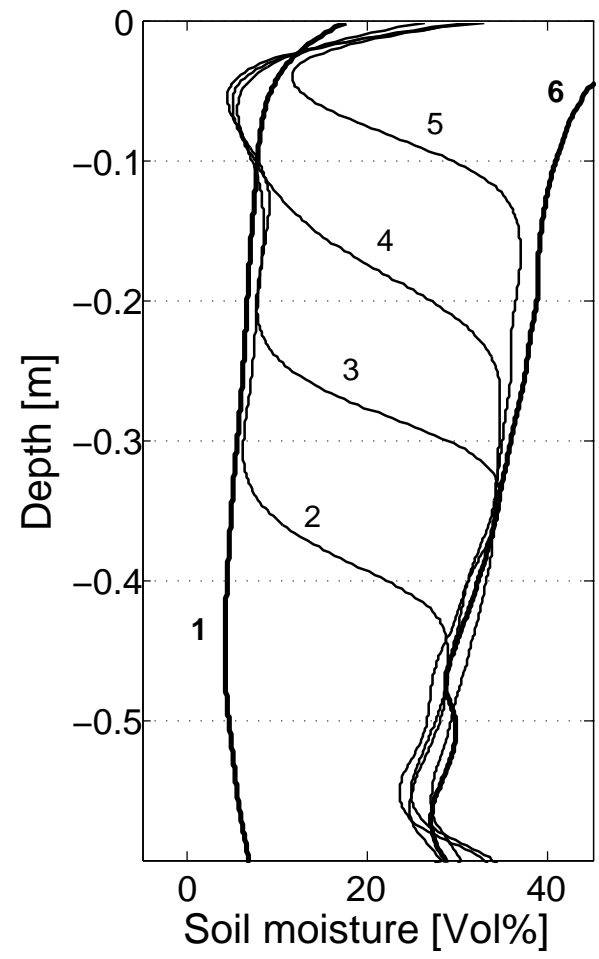

Fig. (4). Reconstructed soil moisture profiles for probes installed in coarse sand. Enveloping bold lines are dry and fully saturated profiles respectively. Water level for waveforms no. 2: $40 \mathrm{~cm}$, no. 3: $30 \mathrm{~cm}$, no. 4: $20 \mathrm{~cm}$, no. $5: 10 \mathrm{~cm}$ below the probe's head according to the measurements in a connected tube.

a) Straight rods.

b) Expanded rods.

Table 3. Reconstructed and Measured Saturated Water Content (Spatial-TDR: Means of Three Probes Per Material)

\begin{tabular}{|c|c|c|c|}
\hline Material & Spatial-TDR $(\mathbf{1 0}-\mathbf{5 0} \mathbf{~ c m})$ & TRIME-TDR & Thermo-Gravimetrically \\
\hline \hline Saturated water content of coarse sand [Vol\%] & $38.0 \pm 1.8$ & $36.6 \pm 1.5$ & $37.2 \pm 1.2$ \\
\hline Saturated water content of silty sand [Vol\%] & $28.8 \pm 3.6$ & $29.2 \pm 0.9$ & $28.1 \pm 0.6$ \\
\hline
\end{tabular}

\subsection{Influence of Changed Probe Geometry}

The effect of an expansion of the probe's rods was investigated during the measurements with coarse sand. As seen in Fig. (3b) the TDR-signals constantly increase between the two reflection points due to a non homogeneous distribution of the line parameter L. Consequently, in the reconstructed soil moisture profile the changed probe geometry results in an apparent continuous decrease of soil moisture with depth (Fig. 4b). The saturated water content is $39 \mathrm{Vol} \%$ in $10 \mathrm{~cm}$ depth, were the rods are hardly expanded. The impact of the stones themselves that have been clamped in between the rods in about $55 \mathrm{~cm}$ depth is not visible in the signals.

\section{DISCUSSION}

\subsection{Performance of the Spatial-TDR Measurement System}

The Spatial-TDR measurement system holds great potential to capture a soil moisture profile in high spatial and temporal resolution. Our experiments confirm that a water table or a capillary fringe can be located in a resolution of some centimetres. The reconstructed water contents are very reli- able for the middle part of the probe (10 to $50 \mathrm{~cm}$ depth). Little differences in the saturated soil moisture profiles might be due to slightly different conditions in the columns (layering of material, air locking).

The measurement itself and the reconstruction of the soil moisture takes only some minutes and consequently allows for scores of measurements in a short time. However, the reconstruction algorithm does not cope with abrupt strong or small scale changes of soil moisture. The reason and the consequences of this fact are explained in the following.

\subsection{Shortcomings of the Reconstruction Algorithm}

The TDR waveform is inversely simulated by modifying the capacitance $\mathrm{C}(\mathrm{x})$ iteratively along the probe. $\mathrm{C}(\mathrm{x})$ is used to derive the final soil moisture profile. But, if the impedance along the waveguide changes suddenly (e.g. at an air-waterinterface or at the probe's head) $\mathrm{C}(\mathrm{x})$ is modified in the reconstruction algorithm as well but much more inertial due to the relatively wide edge of the input signal. Consequently, an oscillation of the capacity distribution can be built up while the optimization algorithm indicates a local minimum. That 


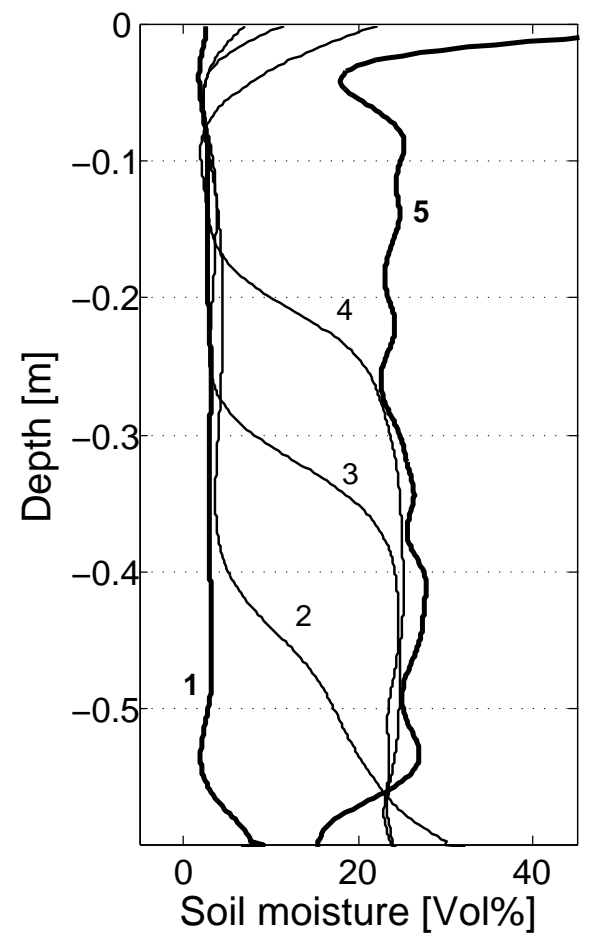

Fig. (5). Reconstructed soil moisture profiles for probes installed in silty sand. Enveloping bold lines are dry and fully saturated profiles, respectively. Measurements have been taken $10 \mathrm{~min}$ (no. 2), $60 \mathrm{~min}$ (no. 3), $170 \mathrm{~min}$ (no. 4) and $230 \mathrm{~min}$ (no. 5) after water supply.

means, up to now, a nonsense strongly oscillating capacity along the probe allows for a good simulation of the TDR waveform. These circumstances are illustrated in Fig. (8). This is an example of the intermediate steps for the reconstruction of the rather strong oscillating soil moisture profile no. 4 in Fig. (7a). Here, the measured and simulated TDRwaveform fit well (Fig. (8a)). However, by the iterative optimization, $\mathrm{C}(\mathrm{x})$ is overestimated in about $15 \mathrm{~cm}$ depth that is just under the sharp air-water-interface. Thereafter $\mathrm{C}(\mathrm{x})$ is underestimated to reach a good fit of the simulated TDRwaveform. This non-realistic distribution of $\mathrm{C}(\mathrm{x})$ is the reason for the oscillation of the finally derived soil moisture.
One step to improve the reconstruction algorithm is the implementation of another optimization approach. But, this might slow down the algorithm. Considering the dispersion of the TDR-100-input-signal along the $15 \mathrm{~m}$ cable a high resolution in object identification cannot be expected. The spatial discretization of $2 \mathrm{~mm}$ that is equal to a resolution of $10-20 \mathrm{~mm}$ should be appropriate concerning the dispersion of the input signal.

\subsection{Suitability for Different Hydrological Investigations}

The Spatial-TDR measurement system is very useful to observe interflow processes in high temporal resolution. Likewise, it is helpful to monitor vertical and lateral water fluxes, e.g. to observe the expansion of saturated areas as documented by [10] and [14]. For that purposes a spatial discretization of 5 to $10 \mathrm{~cm}$ is sufficient and accurate soil moisture values are not required. For some studies relative changes of soil moisture are very useful information. E.g. in [23] the relative saturation in a certain soil depth is used to determine the moisture state of a catchment and to get information on the susceptibility to floods.

[10] showed the capability of the Spatial-TDR to monitor infiltration fronts in a homogeneous loamy sand. But, soils in the field often feature a very heterogeneous texture and structure. Higher precipitation will hardly ever infiltrate as front but rather through macropores, cracks or along roots. Since the base area of the column that is captured by the Spatial-TDR is between only 20 and $25 \mathrm{~cm}^{2}$, the infiltration process might not be seen in the TDR-signals.

For water balance or evaporation studies accurate soil moisture data are required. In that respect the Spatial-TDRsystem is error-prone at present state. Especially the reconstructions for the uppermost part of the soil, an important zone for evaporation studies can not be used. As shown in this study, almost all reconstructions of the saturated soil moisture profile feature a much too high water content in the upper $10 \mathrm{~cm}$ followed by much too low values beneath. This phenomenon occurred in the studies of [10], too, and is caused by the suddenly changing impedance at the probes head as explained above. Furthermore, the contact problem is particularly high in the upper soil due to bioturbation as well as swelling and shrinking effects. Altogether, accuracy

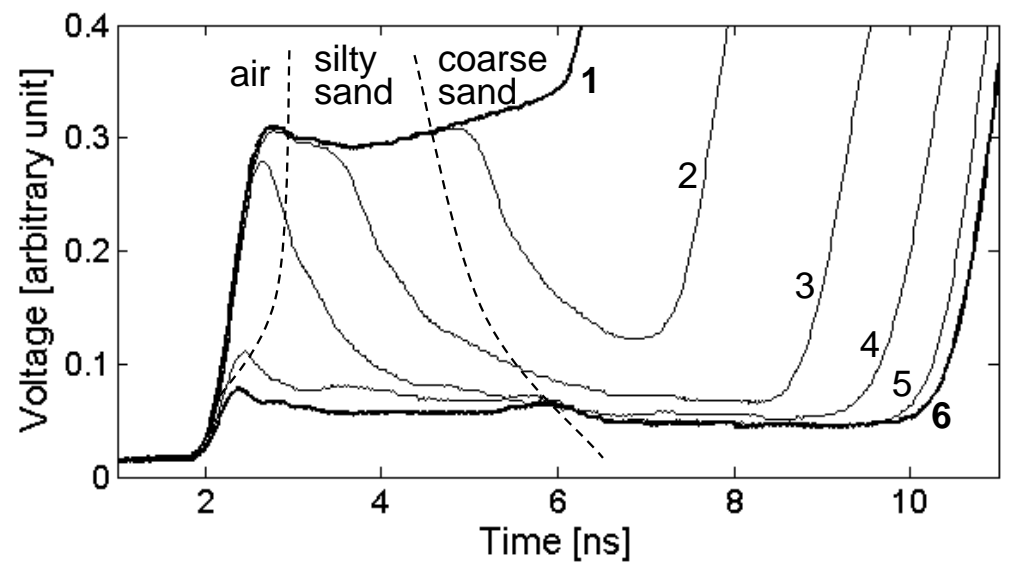

Fig. (6). Measured TDR waveforms for a probe installed in layered material. The dashed lines roughly delineate the range of the respective material. For measurement no. 4 the air gap between the probes head an the material was $10 \mathrm{~cm}$ wide, for no. 5 only $1 \mathrm{~cm}$ and for no. 6 the gap was entirely filled up with wet silty sand. 

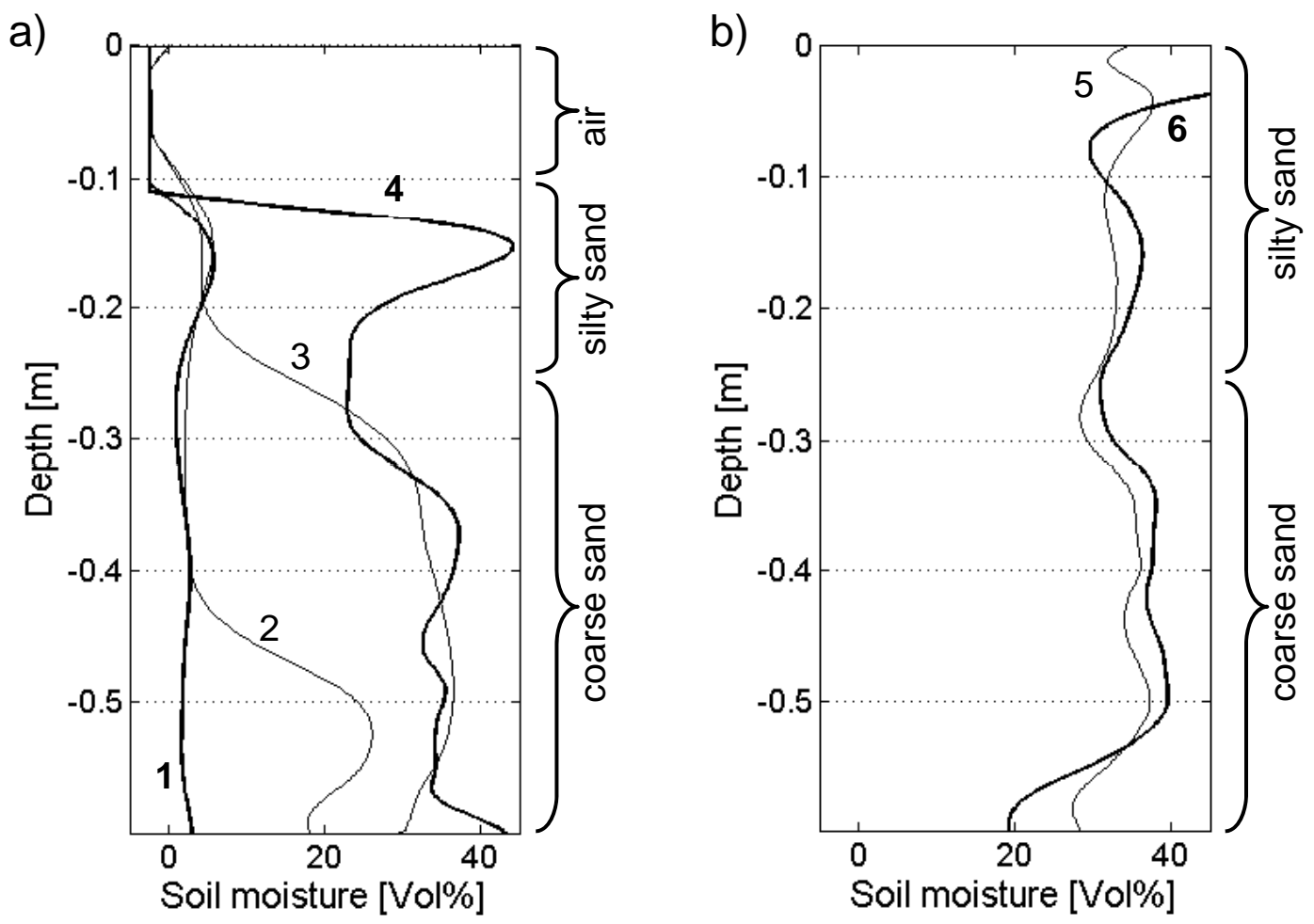

Fig. (7). Reconstructed soil moisture profiles for a probe installed in layered material.

a) Air gap $10 \mathrm{~cm}$ under the probe's head. Measurements have been taken 1 min (no. 2), 10 min (no. 3) and 15 min (no. 4) after water supply. Bold lines indicate the measurements in dry and saturated material.

b) Air gap of $1 \mathrm{~cm}$ (no. 5) and without air gap (no. 6) under the probes head. For both measurements the material was saturated.

a)

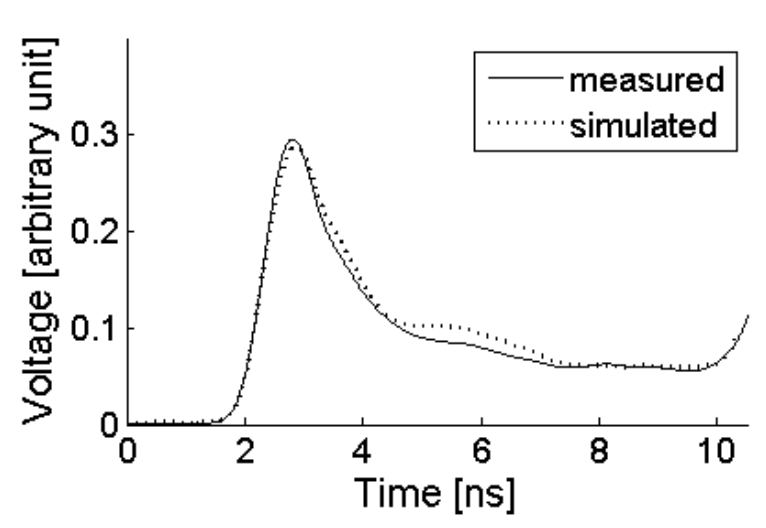

b)

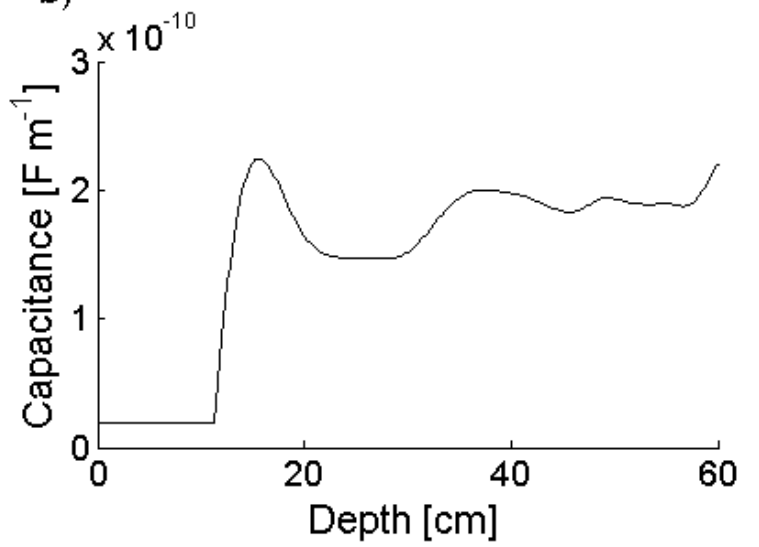

Fig. (8). Results of intermediate steps within the soil moisture reconstruction process (measurement no. 4 in saturated layered material, see Fig. (7a)).

a) Measured and simulated TDR-waveform.

b) Inversely reconstructed distribution of capacitance C (x).

is always a problem in soil moisture measurement and other measurement systems (e.g. tensiometry) are likely to fail in this respect, too.

\subsection{Factors of Uncertainty}

In this section we comment on different factors of uncertainty such as the disregard of the effective conductance $\mathrm{G}$, the impact of an air gap along the rods as well as the effect of the changing probe geometry. Other factors of uncertainty e.g. temperature, salinity and the relationship between di- electric permittivity and soil moisture (Eq. (3)) have not been considered in this article but are discussed in e.g. [17-19].

In this study the impact of $\mathrm{G}(\mathrm{x})$ on the measured TDRSignal has been neglected since we used nearly lossless materials and coated rods. The straight line between the head and end reflection of the measured TDR waveform during wet conditions (Fig. (3a)) confirm this assumption. The waveforms are also straight for the silty sand. In this study, no improvement could be reached by setting $G$ higher than zero. However, natural soils are likely to contain more clay 
and organic material. Here, a material specific empirical relationship between $\mathrm{C}(\mathrm{x})$ and $\mathrm{G}(\mathrm{x})$ has to be defined as for instance given by [24].

Natural soils often feature a change in grain size distribution with depth. To investigate these conditions a layered profile has been set up. Considering only the middle section of the reconstructed profile the saturated water content varies in a reliable way (Fig. (7b)). In this study the transmissionline parameters have not been changed.

An air gap along the probe's rods has a very strong impact on the TDR-waveform as well as on the performance of the reconstruction algorithm. Fig. (6) shows that an air gap of some centimetres below the probes head has a very strong influence on the TDR-waveform. The differences between measurement no. 4 , no. 5 and no. 6 are only due to the up to $10 \mathrm{~cm}$ wide air gap. If the upper soil is nearly saturated the reconstruction of such a sharp air-water-interface is not possible. Consequently, in practical use the entire insertion of the Spatial-TDR-probes is absolutely required.

The effect of changed probe geometry has been shown in Figs. (3b) and (4b). An up to the rods end increasing spacing between the rods results in an constantly increasing TDR waveform and consequently in a constantly decreasing water content with depth. This is consistent with the investigations of [7]. It might be possible to detect such constant systematic variances in field measurements. However, excavations of some probes in the field showed that the spacing between the rods is hardly ever constantly changing but the rods are bent in itself even though the rod holes have been pre-drilled before installation.

\section{CONCLUSIONS AND OUTLOOK}

The here presented Spatial-TDR-approach is very promising and has a lot of benefits compared to other methods. The disturbance of the soil by the $60 \mathrm{~cm}$ long probes is rather small. Furthermore, the spatial discretization as well as the temporal resolution is very high both in measurement and reconstruction. Generally, for the middle part of the profile the reconstructed soil moisture data is reliable. Consequently, the Spatial-TDR can be very useful for studies that aim to capture soil moisture dynamics down to a depth of 50 cm (e.g. in hillslope hydrology).

In this article some shortcomings of the Spatial-TDR are elucidated and factors of uncertainty are discussed from a user's point of view. At present state the occasionally occurring oscillation of the simulated distribution of the capacitance $\mathrm{C}$ seems to be the main challenge. Furthermore, for lossy soils an appropriate relationship between $\mathrm{C}$ and the effective conductance $G$ has to be defined to simulate the distribution of both parameters with only an one-side TDRmeasurement. Nevertheless, the uncertainty of $G$ might be less important for a successful soil moisture reconstruction than other uncertainties related to the installation of the probes. One important point is the lacking contact of the rods with the soil e.g. if the probe intersect any voids or if it is not inserted completely into the soil. The problem is not only the bivalent situation in this void (air or water) but the strong impact on the reconstruction of the soil moisture around this void. Another factor of uncertainty is a changed geometry of the $60 \mathrm{~cm}$ long probes. In our experiments a linear expansion lead to a constantly decreasing soil moisture with depth. In the field the probe geometry is not know but at least, since this is a constant factor, relative changes in soil moisture are still reliable. Last but not least one have to point out, that the advantages of the Spatial-TDR are numerous compared to other soil moisture measurement systems e.g. profile probes or Ground Penetrating Radar. Some of the discussed uncertainties and challenges exist for these measurement systems as well.

Several studies and developments within the TDR measurement technique aiming to derive soil moisture profiles led to substantial technical progress. These measurement systems proved their performance in the laboratory but only some of them in the field $[6,8,25]$. The conditions in the field are very different to those in the laboratory. A close cooperation between developers and users is important to on the one hand focus on the major challenges in development and on the other hand to avoid misuses in field application.

In the future, we are going to interpret the measured Spatial-TDR waveforms itself without reconstructing the soil moisture values. Even if the probe geometry is changed, the material changes or the rods intersect any void the TDR waveform still reflects the moisture state in different depths. Consequently, the shape of the waveform at a certain point can be linked to a certain moisture state of a system or can give a picture of lateral flow processes. These topics will be presented in another article that is based on our field data set.

\section{ACKNOWLEDGEMENT}

We thank Raimund Schneider for valuable suggestions and the use of the soil science laboratory. The support and advices of Rolf Becker are gratefully acknowledged. Many thanks to Cordula Zimper for her helpful hand at various stages. We are thankful for the detailed comments and valuable complements of one anonymous reviewer. The study was funded by the German state Rheinland-Pfalz within the research programme "Wissen schafft Zukunft" and the Forschungsfonds of the University of Trier.

\section{REFERENCES}

[1] Lundstedt J, He S. A time-domain optimization technique for the simultaneous reconstruction of the characteristic impedance, resistance and conductance of a transmission line. J Electromagn Waves Appl 1996; 10: 581-602.

[2] Oswald B, Benedickter HR, Bächtold W, Flühler H. Spatially resolved water content profiles from inverted time domain reflectometry signals. Water Res 2003; 39(12): 1357-66.

[3] Heimovaara TJ, Huisman JA, Vrugt JA, Bouten W. Obtaining the spatial distribution of water content along a TDR probe using the SCEM-UA Bayesian inverse modelling scheme. Vadose Zone J 2004; 3: 1128-45.

[4] Schlaeger S. A fast TDR-inversion technique for the reconstruction of spatial soil moisture content. Hydrol Earth Syst Sci 2005; 9: 481-92.

[5] Greco R. Soil water content inverse profiling from single TDR waveforms. J Hydrol 2006; 317: 325-39.

[6] Leidenberger P, Oswald B, Roth K. Efficient reconstruction of dispersive dielectric profiles using time domain reflectometry (TDR). Hydrol Earth Syst Sci 2006; 10: 209-32.

[7] Bänninger D, Wunderli H, Nussberger M, Flühler H. Inversion of TDR signals - revisited. J Plant Nutr Soil Sci 2008; 171: 137-45.

[8] Zehe E, Graeff T, Morgner M, Bauer A, Bronstert A. Plot and field scale soil moisture dynamics and subsurface wetness control on runoff generation in a headwater in the Ore Mountains. Hydrol Earth Syst Sci Discuss 2009, 6, 7503-7537.

[9] Robinson DA, Jones SB, Wraith JM, Or D, Friedman SP. A review of advances in dielectric and electrical conductivity measurement 
in soils using time domain reflectometry. Vadose Zone J 2003; 2: 444-75.

[10] Becker R. Spatial time domain reflectometry for monitoring transient soil moisture profiles. mitteilungen des instituts für wasser und gewässerentwicklung. University of Karlsruhe, 2004; Heft 228.

[11] Hübner C, Schlaeger S, Becker R et al. Advanced measurement methods in time domain reflectometry for soil moisture determination. In: Kupfer K, Ed. Electromagnetic Aquametry. New York: Springer, Berlin, Heidelberg 2005; Chapter 14: pp. 317-47.

[12] Scheuermann A, Huebner C, Schlaeger S et al. Spatial time domain reflectometry and its application for the measurement of water content distributions along flat ribbon cables in a full-scale levee model. Water Res 2009; 45: doi:10.1029/2008WR007073.

[13] Stacheder M, Hübner C, Schlaeger S, Brandelik A. Combined TDR and low frequency permittivity measurements for continuous snow wetness and snow density determination. In: Kupfer K, Ed. Electromagnetic Aquametry. Springer, Berlin 2005; Chapter 16: pp. 367-82.

[14] Schädel W. Schritte zur Verbesserung der Hochwasserfrühwarnung mittels Online-Bodenfeuchtemessungen. Ph.D. thesis: Mitteilungen des Instituts für Wasser und Gewässerentwicklung - Bereich Wasserwirtschaft und Kulturtechnik der Universität Karlsruhe (TH), 2006, Heft 234.

[15] Knight JH, Ferré TPA, Rudolph DL, Kachanoski RG. A numerical analysis of the effects of coatings and gaps upon relative dielectric permittivity measurement with time domain reflectometry. Water Res 1997; 33: 1455-460.

[16] Zegelin SJ, White I, Russell GF. A critique of the time domain reflectometry technique for determining field soil-water content. In: Topp GC, Ed. advances in measurement of soil physical properties: bringing theory into practice. SSSA special publication, Madiscon 1992; pp. 187-208.
[17]

Baumhardt RL, Lascano RJ, Evett SR. Soil Material, Temperature, and Salinity Effects on Calibration of Multisensor Capacitance Probes. Soil Sci Soc Am J 2000; 64: 1940-1946.

[18] Verhoef A, Fernández-Gálvez J, Diaz-Espejo A, Main BE, ElBishti M. The diurnal course of soil moisture as measured by various dielectric sensors: Effects of soil temperature and the implications for evaporation estimates. J Hydrol 2006; 321: 147-162.

[19] Wraith JM, Or D. Temperature effects on soil bulk dielectric permittivity measured by time domain reflectometry: Experimental evidence and hypothesis development. Water Res 1999; 35-2: 3629.

[20] Becker R, Schlaeger S. Spatial time domain reflectometry with rod probes. Proceedings ISEMA 6th Conference on Electromagnetic Wave Interaction with Water and Moist Substances, Weimar 2005; pp. 140-9.

[21] Schlaeger S. Inversion von TDR-Messungen zur Rekonstruktion räumlich verteilter bodenphysikalischer Parameter, Ph.D. thesis. Veröffentlichungen des Institutes für Bodenmechanik und Felsmechanik der Universität Fridericiana, Karlsruhe 2002; vol. 156.

[22] Topp GC, Davis JL, Annan AP. Electrodynamic determination of soil water content: measurements in coaxial transmission lines. Water Res 1980; 16: 574-82.

[23] Casper M, Gemmar P, Gronz O, Johst M, Stüber M. Fuzzy-logic based rainfall runoff modelling by using soil moisture measurements as representations for system state. Hydrol Sci 2007, Special issue: Hydroinformatics; 52(3): 478-90.

[24] Hakansson G. Reconstruction of soil moisture profile using timedomain reflectometer measurements. Master thesis TRITA-TETEX 97-6, Royal Institute of Technology, Department of Electromagnetic Theory, Stockholm 1997.

[25] Wollschläger U, Pfaff T, Roth K. Field-scale apparent hydraulic parameterisation obtained from TDR time series and inverse modelling. Hydrol Earth Syst Sci 2009; 13: 1953-66.

(C) Johst et al.; Licensee Bentham Open.

This is an open access article licensed under the terms of the Creative Commons Attribution Non-Commercial License (http://creativecommons.org/licenses/by-nc/3.0/) which permits unrestricted, non-commercial use, distribution and reproduction in any medium, provided the work is properly cited. 